\title{
ACUTE LEAD POISONING IN AN INDOOR FIRING RANGE
}

\author{
Ladislav Štěpánek ${ }^{1,2}$, Marie Nakládalová ${ }^{1,2}$, Viktor Klementa ${ }^{3,4}$, Veronika Ferenčíková \\ ${ }^{1}$ University Hospital Olomouc, Olomouc, Czech Republic \\ Department of Occupational Medicine \\ ${ }^{2}$ Palacký University Olomouc, Olomouc, Czech Republic \\ Faculty of Medicine and Dentistry, Department of Occupational Medicine \\ ${ }^{3}$ University Hospital Olomouc, Olomouc, Czech Republic \\ Department of Internal Medicine III - Nephrology, Rheumatology and Endocrinology \\ ${ }^{4}$ Palacký University Olomouc, Olomouc, Czech Republic \\ Faculty of Medicine and Dentistry, Department of Internal Medicine III - Nephrology, Rheumatology and Endocrinology \\ ${ }^{5}$ Comenius University in Bratislava, Slovak Republic \\ Jessenius Faculty of Medicine in Martin, Clinic of Occupational Medicine and Toxicology
}

\begin{abstract}
The presented case demonstrates that acute lead poisoning may occur due to just short-term exposure to a mixture of lead-containing dust and ammunition. Such exposure may result in high blood lead levels persisting for years in the absence of any symptoms. A middle-aged male with a history of an approximately 7-day cleanup of an old recreational firing range with large ammunition and dust deposits presented to an emergency department with abdominal pain, dyspnea, fatigue and impaired cognitive function. Given his occupational history, specific tests were performed that showed high lead concentrations in both blood and urine. The patient was diagnosed with acute lead poisoning. He was started on chelation therapy that improved both clinical and laboratory parameters. Over a subsequent nearly 3-year follow-up, the patient's blood lead levels fluctuated and continued to be increased. Given the absence of other sources of lead exposure, these were likely due to the formation of bone deposits. Med Pr 2020;71(3):375-9
\end{abstract}

Key words: lead poisoning, blood lead level, occupational exposure to lead, urine lead level, anemia, chelation therapy

Corresponding author: Ladislav Štěpánek, University Hospital Olomouc, Department of Occupational Medicine,

I.P. Pavlova 185/6, 77900 Olomouc, Czech Republic, e-mail: stepanek.ladislav@gmail.com

Received: September 3, 2019, accepted: December 7, 2019

\section{INTRODUCTION}

Despite extensive efforts to reduce the industrial use of lead, this metal continues to be commonly used in many industries, including ammunition production [1-3]. In occupational medicine practice, chronic forms of lead poisoning are usually encountered. However, significant exposure may occur in occupations that are not considered to be "at risk" [4]. An increasing amount of evidence suggests that the global use of lead-containing ammunition is an important source of lead exposure. Shooting and time spent at firing ranges are an integral part of many occupations (e.g., the police or military) $[5,6]$.

\section{CASE REPORT}

A 46-year-old male presented to an emergency department with his condition gradually worsening from full health over the previous 3 days. The patient reported having fatigue, headache, malaise, anxiety, nervousness, problems with memory and orientation, insomnia and, gradually, twitching in the thighs, finger numbness with paresthesia, and chills but no fever. Later, he developed occasional dyspnea, hypogastric pain radiating bilaterally into the lumbar region, and epigastric cramps. He also reported severe appetite loss and constipation. Interestingly, his occupational history included considerable physical strain when cleaning an 
old recreational firing range (established in the 1970s) before reconstruction. While wearing no personal protective equipment, he had been removing thick deposits of dust mixed with ammunition fragments for at least $6 \mathrm{~h} /$ day for 7 days before the onset of the first symptoms. The patient, working his entire life as a fitness trainer with no apparent lead exposure, had never been to the firing range before the cleanup started. His medical history was uneventful. Six weeks before the cleanup, just by coincidence, the patient had got a comprehensive regular health check-up comprising laboratory tests including a complete blood count (CBC) and basic biochemical parameters which showed normal results (Table 1).

During the initial examination in the emergency department, his $\mathrm{CBC}$ and white blood cell differential revealed normocytic anemia and mild leukocytosis with mild neutrophilia (84.7\%) and lymphocytopenia $(7.8 \%)$. He was also found to have an increased reticulocyte count (3.4\%) and basophilic stippling of red blood cells. The other common laboratory tests yielded elevated serum liver transaminase, bilirubin and creatinine levels, and a decreased glomerular filtration rate (Table 1). Repeated measurements showed an arterial blood pressure of 145-155/100-105 mm Hg.

Electrocardiography, chest and abdominal x-rays, abdominal ultrasonography and neurological examinations, including electromyography of the limb nerves, showed no pathological findings. Given the patient's exposure to dust from the firing range, as ascertained from his occupational history, and suspicious clinical manifestations in the absence of signs clearly suggestive of any other condition, specific toxicological tests were indicated. The tests detected an elevated blood lead level (BLL) and urine lead level (ULL) in a 24-h urine sample (Table 2). The concentration of 5-aminolevulinic acid (5-ALA) in the collected urine was $8654 \mu \mathrm{g} / \mathrm{dl}$. The serum iron concentration was $249.7 \mu \mathrm{g} / \mathrm{dl}$. Psychological assessment showed psychomotor slowing, memory impairment and insomnia. A diagnosis was made of acute lead poisoning requiring immediate initiation of chelation therapy.

Therefore, 7 days after the onset of the first symptoms, initial symptomatic therapy was followed by the administration of succimer (Succicaptal), initially $30 \mathrm{mg} / \mathrm{kg} /$ day in 3 doses/day for 5 days, and then $30 \mathrm{mg} /$ $\mathrm{kg} /$ day in 2 doses/day for another 2 weeks, as recommended by the drug manufacturer. The selected therapy proved successful. Not only the clinical manifestations resolved rapidly but there were considerable decreases

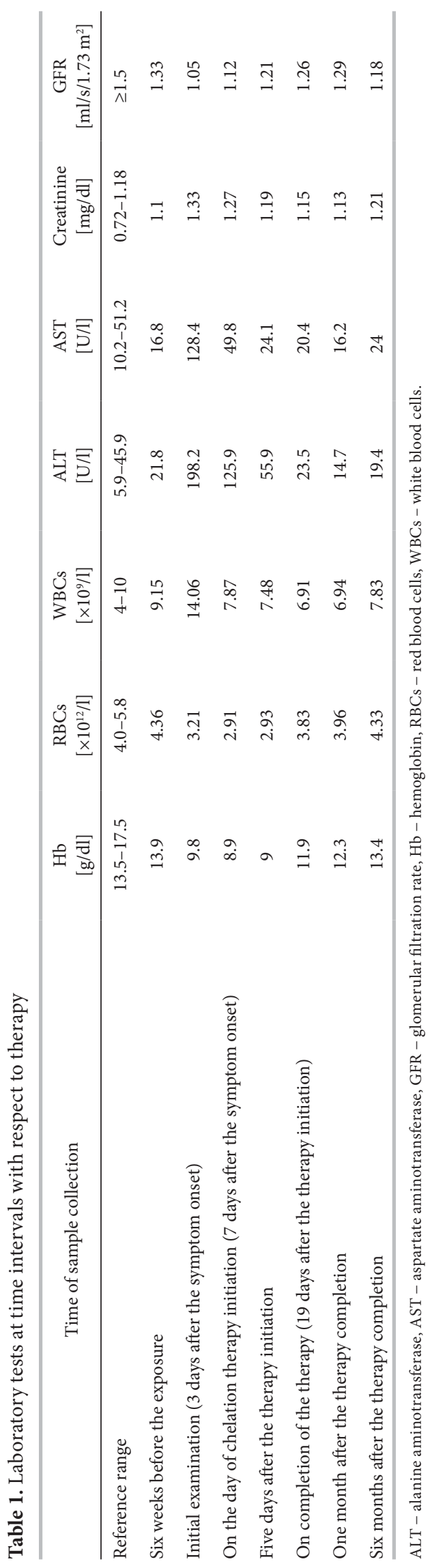


Table 2. Blood (BLL) and urine (ULL) lead levels throughout the follow-up

\begin{tabular}{|c|c|c|}
\hline Time of sample collection & $\begin{array}{c}\mathrm{BLL}^{*} \\
{[\mu \mathrm{g} / \mathrm{dl}]}\end{array}$ & $\begin{array}{l}\mathrm{ULL} / 24 \mathrm{~h} \\
{[\mu \mathrm{g} / 24 \mathrm{~h}]}\end{array}$ \\
\hline Initial examination/before the therapy initiation & 81.9 & 134 \\
\hline On completion of the therapy & 32.0 & 389 \\
\hline One month after the therapy completion & 44.4 & 64 \\
\hline Six months after the therapy completion & 40.4 & 214 \\
\hline Fifteen months after the therapy completion & 54.6 & 142 \\
\hline Seventeen months after the therapy completion & 40.2 & - \\
\hline Twenty-five months after the therapy completion & 46.6 & 18 \\
\hline
\end{tabular}

${ }^{*}$ Maximum value for the exposed according to the Czech law: $40 \mu \mathrm{g} / \mathrm{dl}$ [8].

in both 5-ALA in collected urine samples $(222 \mu \mathrm{g} / \mathrm{dl}$ at 5 days after therapy initiation) and BLL, accompanied by an elevated ULL (Table 2). The above clinical symptoms, including high blood pressure, resolved 2 weeks after the therapy completion. At the onset of his symptoms, the patient no longer did the dangerous work and the firing range cleanup was completed by a professional firm so that valid hygiene norms were adhered to. The firing range was equipped with an air circulation system and lamella bullet traps. Occasionally, the patient works as an instructor, spending no more than $2 \mathrm{~h}$ /week shooting or on the range premises. $\mathrm{He}$ was thoroughly educated about the need for and ways of elimination of all potential sources of lead exposure, both occupational and non-occupational, and invited for follow-up check-ups (Table 2).

As the patient continued to have elevated BLLs, despite being completely asymptomatic, potential sources of lead exposure were thoroughly reassessed approximately 2 years after the therapy completion. Neither occupational nor non-occupational causes of elevated BLLs were discovered in the patient's life. The only possible exception was his habit of chewing one particular brand of tobacco that had lasted for several years. However, tests of 5 samples of various batches of the tobacco showed only a minimum lead content, well below the limit for food supplements set by the applicable legislation $(3 \mathrm{mg} / \mathrm{kg}$ ) [7]. Moreover, examinations of a full-time shooting instructor employed at the firing range only after the reconstruction repeatedly showed normal BLLs [8].

Both BLL and ULL were determined using atomic absorption spectrometry with electrothermal atomiza- tion on Varian Spectrometer AA240Z (LabX, Midland, Ontario, Canada) with GTA120 Graphite Tube Atomizer (Agilent, Santa Clara, CA, USA). The whole blood samples were mineralized with $65 \%$ nitric acid using microwave reactor CEM Mars 5 (CEM Corporation, Matthews, NC, USA). After mineralization, the samples were diluted with deionized water and analyzed. The urine samples were diluted 10 -fold with deionized water before the analysis. The palladium modifier was used for the analysis. The analytical method was validated according to the Czech Clinical Chemistry Society (ČSKB ČLS JEP) guidelines and the limit of quantitation was $5.0 \mathrm{nmol} / \mathrm{l}$. The method is linear at least in the range of $5.0-500.0 \mathrm{nmol} / \mathrm{l}$. The internal quality control is performed with Lyphochek Whole Blood Metals Control, 3 levels (Hercules, CA, USA), and the external quality control is performed twice a year using Trace Elements (SEKK, Pardubice, Czech Republic). The combined uncertainty of the measurement is $12.8 \%$.

\section{DISCUSSION}

The present case demonstrates the potential of dust from lead-containing ammunition to produce clinically significant acute lead poisoning. Indoor firing ranges are a source of lead exposure and elevated BLLs among employees, their families, and customers. The use of firing ranges is integrally associated with the formation of lead-containing dust [9]. An analysis of 36 available articles on lead exposure in both recreational shooters and occupational users of firing ranges revealed more 
than 1 subject with BLL $>10 \mu \mathrm{g} / \mathrm{dl}$ in 31 studies, BLL $>20 \mu \mathrm{g} / \mathrm{dl}$ in 18 studies, BLL $>30 \mu \mathrm{g} / \mathrm{dl}$ in 17 studies, and BLL $>40 \mu \mathrm{g} / \mathrm{dl}$ in 15 studies [5]. Elevated BLLs in shooters depend on the caliber of weapon fired, the number of bullets discharged, and the introduction of and adherence to protective measures at firing ranges. Thus, targeted protective measures at firing ranges are needed that include changing clothing and footwear after shooting, banning smoking and eating at firing ranges, controlling access to the premises, preferring lead-free bullets, improving ventilation, and using wet mopping. Regular BLL monitoring in both firing range personnel and users may also prove beneficial $[5,9]$.

Given its physical and chemical properties, lead tends to deposit, mainly in the bones from where it is slowly, over many years, released into the blood and eliminated from the body through urine $[1,10]$. Bone lead mobilization heightens during times of increased bone turnover, such as pregnancy, lactation, and hyperthyroidism [11]. Traditionally, BLLs have been considered a marker of recent exposure; however, accelerated bone lead mobilization may be the cause of BLL elevation as well [12].

Although succimer therapy considerably reduced the reported patient's BLL, in the subsequent follow-up period, his BLLs fluctuated within a certain interval, with only a slight decrease at the end of the follow-up. There have been reports of lead poisoning caused by chewing contaminated tobacco [13]. Therefore, the authors tried to rule out this possibility by testing several random batches of tobacco with negative results. Although no other source of lead poisoning has been found in the patient, undetected, mainly non-occupational, exposure cannot be completely excluded. It seems that the aforementioned short, yet extreme, exposure was sufficient to produce resistant deposits in the body. The patient works as a full-time fitness trainer exercising intensely even in his free time. The skeleton is a dynamic tissue continuously exposed to bone removal and regeneration, especially in response to mechanical loading and exercise [14]. It is questionable whether the patient's physical activity could mobilize lead from the bones, thus contributing to the persisting elevation of BLLs.

\section{CONCLUSIONS}

The case suggests that indoor firing range premises can be a source of severe acute lead poisoning. At in- door firing ranges, consistent health protection must not be underestimated. Attempts to reduce the use of lead-containing ammunition are not unwarranted.

\section{REFERENCES}

1. Barry V, Todd AC, Steenland K. Bone lead associations with blood lead, kidney function and blood pressure among US, lead-exposed workers in a surveillance programme. Occup Environ Med. 2019;76(5):349-54, https://doi.org/10.1136/ oemed-2018-105505.

2. Green RE, Pain DJ. Risks to human health from ammunition-derived lead in Europe. Ambio. 2019;48(9):954-68, https://doi.org/10.1007/s13280-019-01194-x.

3. Borghini A, Gianicolo EA, Andreassi MG. Usefulness of biomarkers as intermediate endpoints in health risks posed by occupational lead exposure. Int J Occup Med Environ Health. 2016;29(2):167-78, https://doi.org/10.13075/ ijomeh.1896.00417.

4. Gidlow DA. Lead toxicity. Occup Med (Lond). 2015;65(5): 348-56, https://doi.org/10.1093/occmed/kqv018.

5. Laidlaw MA, Filippelli G, Mielke H, Gulson B, Ball AS. Lead exposure at firing ranges-a review. Environ Health. 2017;16(1):34, https://doi.org/10.1186/s12940-017-0246-0.

6. Vandebroek E, Haufroid V, Smolders E, Hons L, Nemery B. Occupational exposure to metals in shooting ranges: A biomonitoring study. Saf Health Work. 2019;10(1):8794, https://doi.org/10.1016/j.shaw.2018.05.006.

7. Commission Regulation (EC) No 629/2008 of 2 July 2008 amending Regulation (EC) No 1881/2006 setting maximum levels for certain contaminants in foodstuffs [Internet]. European Brussels: Commission; 2008 [cited 2019 Sep 1]. Available from: https://eur-lex.europa.eu/legal-content/EN/ALL/?uri=CELEX\%3A32008R0629.

8. [Decree No. 181/2015 Coll. amending the Decree No. 432/ 2003 Coll., enacting the conditions for job categories, limit values of biological exposure tests, conditions for sampling of biological materials for biological exposure tests and requirements of reports on work with asbestos and biological agents, as amended by Decree No. 107/2013 Coll.]. Ministry of Justice, Government of the Czech Republic: Prague; 2015 [cited 2019 Sep 1]. Available from: https://www.zakonyprolidi.cz/cs/2003-432. Czech.

9. Beaucham C, Page E, Alarcon WA, Calvert GM, Methner M, Schoonover TM, et al. Indoor firing ranges and elevated blood lead levels - United States, 2002-2013. MMWR Morb Mortal Wkly Rep. 2014;63(16):347-51.

10. Dapul H, Laraque D. Lead poisoning in children. Adv Pediatr. 2014;61(1):313-33, https://doi.org/10.1016/j.yapd. 2014.04.004. 
11. Oliveira S, Aro A, Sparrow D, Hu H. Season modifies the relationship between bone and blood lead levels: the Normative Aging Study. Arch Environ Health. 2002;57(5):46672, https://doi.org/10.1080/00039890209601439.

12. Kim HC, Jang TW, Chae HJ, Choi WJ, Ha MN, Ye BJ, et al. Evaluation and management of lead exposure. Ann Occup Environ Med. 2015;27:30, https://doi.org/10.1186/s40557015-0085-9.

13. El Zahran T, Ralston A, King A, Hindman D, Morgan BW. Elevated lead level from a tobacco source requiring che- lation in a 12-year-old child. Clin Toxicol (Phila). 2018; 56(11):1159-61, https://doi.org/10.1080/15563650.2018. 1458990 .

14. Qi Z, Liu W, Lu J. The mechanisms underlying the beneficial effects of exercise on bone remodeling: Roles of bone-derived cytokines and microRNAs. Prog Biophys Mol Biol. 2016;122(2):131-9, https://doi.org/10.1016/j.pbiomolbio.2016.05.010.

This work is available in Open Access model and licensed under a Creative Commons Attribution-NonCommercial 3.0 Poland License - http://creativecommons.org/licenses/by-nc/3.0/pl/deed.en. 